\title{
Analysis of Factors Affecting Bearing Capacity of Large Diame- ter Single Piles of Offshore Wind Power under Earthquake Loads
}

\author{
Yazhou Li ${ }^{1 *}$, Li Dong ${ }^{1}$ \\ ${ }^{1}$ College of Civil Engineering and Architecture, Shandong University of Science and Technology, Qingdao, 266590, China
}

\begin{abstract}
The offshore wind turbine single pile foundation structure is simple and easy to install, but in the earthquake environment, large horizontal displacement is easy to occur, which affects the safe operation of offshore wind turbines. For this reason, the bearing characteristics and influencing factors of large-diameter single-pile offshore wind power under earthquake load are analyzed. The Mohr-Coulomb model is used as the model. The ABAQUS is used to construct the large-scale single-pile finite element model of offshore wind power. Loads and analysis of bearing characteristics and influencing factors of large-diameter singlepile offshore wind power under seismic loading. It is found that the increase of pile foundation depth will significantly reduce the horizontal displacement at the top of single pile. After increasing to a certain extent, it has no significant effect on the development of horizontal deformation of large diameter single pile; with the increase of pile diameter and wall thickness, The deformation of large diameter single pile foundation is reduced, but the influence of the pile foundation thickness on the horizontal deformation of the large diameter single pile foundation is no longer significant.
\end{abstract}

\section{Introduction}

With the rapid development of China's economy and wind power technology, offshore wind power has become an important part of the world's renewable energy development. The single pile foundation is a common basic form of offshore wind power in China [1]. It is mainly supported by a single support column. It has a simple structure, convenient processing and transportation, quick installation and clear force. It has a wide range of applications in offshore wind power projects [23]. However, the pile foundation diameter has high requirements for construction equipment. The large diameter single pile foundation is affected by earthquake, wind, wave and other loads during service. Under this load, the large diameter single pile foundation may be Large deformation will occur, affecting the normal operation of offshore wind turbines.

In the earthquake, the lateral development of the soil often causes damage to the pile foundation, and light cracks occur, which in turn causes the upper structure to tilt or flip [4-5]. A series of studies have been carried out on the bearing characteristics and seismic loading characteristics of large-diameter single-pile offshore wind power. In theory, Hsiung (2003) and so on through theoretical analysis, proposed the calculation method of bearing capacity of single pile foundation under horizontal load [6]. In terms of experiments, Werasak Raongjant (2011) carried out an experimental study on the seismic behavior of single piles in sand [7]; Banerjee et al. (2013) performed a centrifuge shaker test on a single pile em- bedded in earthquake-inspired clay. The experimental results show that The degree of soil pile interaction depends on the seismic load on the pile top [8]. In terms of numerical simulation, Yan Maotian, Lu Aizhong et al. (2005) considered the interaction effect of pile-soil, established a finite element calculation model for seismic response analysis of pile foundation structures, and carried out the overall finite element numerical calculation in the time domain. The structural analysis method and the finite element numerical calculation method verify the validity of the finite element calculation model [9]; Liao. et al. (2006) studied the numerical simulation of the parallel seismic test of single pile foundation and established the axisymmetric finite element (FE). The model explains the displacement performance of a single pile foundation under seismic loading [10]. It can be seen that the existing research mainly adopts two methods: theoretical analysis and finite element analysis. The research content focuses on the bearing performance of single pile foundation, but the large-diameter single pile bearing of offshore wind power in complex environment (earthquake, wind, wave, etc.) Characteristic studies are still lacking. Therefore, based on the previous research results, the ABAQUS finite element method is used to study the bearing characteristics of large-diameter single-pile offshore wind power under seismic loading, and the factors such as depth, diameter and thickness of pile foundation are analyzed to support large-diameter singlepile offshore wind power. The influence of characteristics provides reference and guidance for the design and optimization of large-diameter single-pile offshore wind power.

*Corresponding Author: Yazhou Li; email:912628666@qq.com 


\section{The Establishment of Finite Ele- ment Model}

The main method is to use finite element numerical simulation method to analyze the bearing characteristics of large-diameter single-pile offshore wind power with earthquake as load. Combined with the finite element software ABAQUS, the constitutive model construction, unit type selection, mesh division, boundary condition setting, and seismic load are applied to complete the finite element model construction of large-diameter single-pile offshore wind power.

\subsection{Constitutive Model}

At present, the numerical analysis technology of the horizontal bearing capacity of pile foundation is relatively mature. Numerical simulation methods include finite element, finite difference and discrete element method [11-12], in which finite element numerical simulation is widely used in pile foundation engineering. The Mohr-Coulomb model is used to calculate the actual situation.

At present, the Mohr-Coulomb failure and strength criterion is widely used in geotechnical engineering. The Mohr-Coulomb failure model is shown in Figure 1.

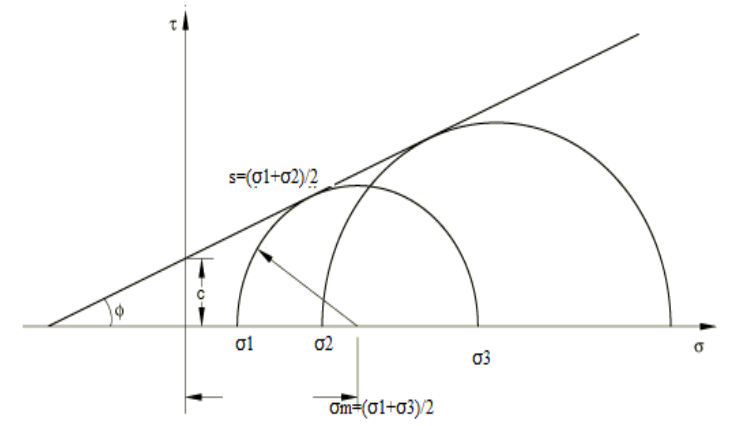

Figure 1. Mohr-Coulomb failure model.
The yield surface function of the model:

$$
F=R_{m c} q-p \tan \varphi-c=0
$$

In this part,

$$
\begin{gathered}
R_{m c}=\frac{1}{\sqrt{3} \cos \varphi} \sin \left(\Theta+\frac{\pi}{3}\right)+\frac{1}{3} \cos \left(\Theta+\frac{\pi}{3}\right) \tan \varphi \\
\cos (3 \Theta)=\frac{r^{3}}{q^{3}}
\end{gathered}
$$

In this part:

$R_{m c}-$ a function of the shape of the yield surface in the $\pi$ plane; $\varphi$ _- Tilt angle on the M-C yield surface; $c-$ Material cohesion; $\varphi-$ Friction angle of the soil; $\Theta$ Limited angle; $q$ _ Equivalent stress; $r$ Partial stress invariant.

The damage criterion of the model:

$\tau=\mathrm{c}-$ otag $\emptyset$

In this part, $\tau$ - Shear strength; $\sigma-$ Normal stress; $\emptyset-—$ Friction angle.

\subsection{Parameter design}

Combined with the application status, actual use requirements and design requirements of large-diameter single-pile offshore wind power, steel Q235 is used as a single pile foundation structural material. The performance parameters of the large-diameter single-pile foundation structure of offshore wind power and its contact with each layer of soil are shown in Tables 1 and 2 .

Table 1. Single pile foundation material parameters.

\begin{tabular}{cccccccc}
\hline $\begin{array}{c}\text { Parame- } \\
\text { ter }\end{array}$ & $\begin{array}{c}\text { Pile diame- } \\
\text { ter } / \mathrm{m}\end{array}$ & $\begin{array}{c}\text { Wall thick- } \\
\text { ness } / \mathrm{mm}\end{array}$ & $\begin{array}{c}\text { Buried } \\
\text { depth } / \mathrm{m}\end{array}$ & $\begin{array}{c}\text { Elastic Modu- } \\
\text { lus } / \mathrm{GPa}\end{array}$ & $\begin{array}{c}\text { Poisson's } \\
\text { ratio }\end{array}$ & $\begin{array}{c}\text { Density } \\
\mathrm{kg} / \mathrm{m}^{3}\end{array}$ & $\begin{array}{c}\text { Yield } \\
\text { Strength } / \\
\mathrm{MPa}\end{array}$ \\
\hline $\mathrm{Q} 235$ & 4 & 5 & 45 & $2.1 \times 10^{5}$ & 0.3 & 7850 & 235 \\
\hline
\end{tabular}

Table 2. Performance parameters of large-diameter single-pile foundation structure contact soil layer material.

\begin{tabular}{cccccc}
\hline Soil layer & $\begin{array}{c}\text { Severe } \\
\mathrm{kN} / \mathrm{m}^{3}\end{array}$ & $\begin{array}{c}\text { Elastic Modulus } \\
\text { /MPa }\end{array}$ & $\begin{array}{c}\text { Poisson's } \\
\text { ratio }\end{array}$ & $\begin{array}{c}\text { Thickness } \\
/ \mathrm{m}\end{array}$ & $\begin{array}{c}\text { Shear strength } \\
/ \mathrm{kPa}\end{array}$ \\
\hline $\begin{array}{c}\text { Soft-slightly hard silty } \\
\text { clay }\end{array}$ & 7.6 & 30.2 & 0.20 & 7.3 & 17 \\
Medium dense silt & 8.2 & 36.6 & 0.21 & 7.5 & 26 \\
Fine sand and sandy silt & 9.0 & 44.7 & 0.22 & 2.9 & 30 \\
Dense silt & 9.2 & 50.0 & 0.20 & 9 & 35 \\
Medium dense silt & 9.2 & 58.2 & 0.18 & 2.5 & 41 \\
\hline
\end{tabular}




$$
\text { Hard silty clay }
$$

\subsection{Meshing}

The three-dimensional finite element calculation model of large-diameter single-pile foundation structure for offshore wind power is constructed. The diameter of single pile foundation is $4 \mathrm{~m}$, the pile foundation thickness is $0.05 \mathrm{~m}$, and the buried column length is $45 \mathrm{~m}$.

The offshore wind power large-diameter singlepile foundation structure analysis block adopts the S4R analysis block in the finite element calculation program ABAQUS unit library, and the pile surrounding soil analysis unit adopts the C3D8R unit. The C3D8R device has freedom of motion and pore pressure, which is beneficial to solve the problem of stress/stress coupling in geotechnical engineering ${ }^{[13]}$. The pile are obtained, as shown in Figure 2.

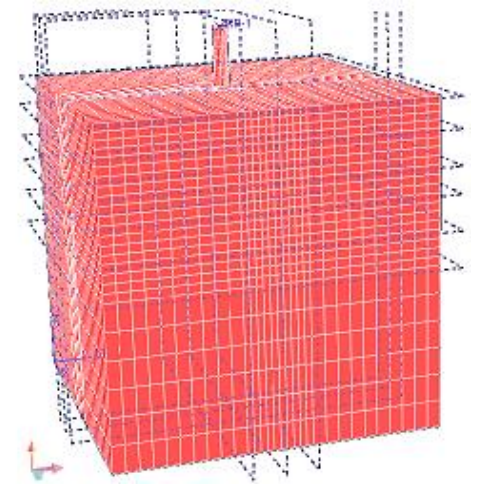

Figure 2. Large-diameter single-pile foundation structure and meshing of surrounding soil.

\subsection{Boundary conditions}

In the analysis of the bearing characteristics of largediameter single-pile offshore wind power under seismic loading, the key is to limit the bottom soil $\mathrm{X}, \mathrm{Y}$
0.15

10.8

100

and $\mathrm{Z}$ displacement in three directions. The bottom of the large-diameter single-pile foundation structure of offshore wind power is considered to be fixed between the bottom and the seabed soil. Therefore, when carrying out the bearing characteristics analysis, the full constraint is imposed on the bottom of the large-diameter single-pile foundation structure of the offshore wind power ${ }^{[14]}$. The diameter of the soil is $60 \mathrm{~m}$ and the height is $50 \mathrm{~m}$. In order to reduce the boundary conditions and the influence of various factors on the analysis results, the soil boundary is taken as 5 times. In addition, in the seismic wave dynamic analysis, the regional boundary may cause wave reflection, which affects the accuracy of numerical analysis. Therefore, Rayleigh damping is used, and the damping ratio is calculated as 0.01 . Therefore, the boundary conditions and constraints of the largediameter single-pile foundation structure of the offshore wind power and the finite element model of the surrounding soil can be obtained.

\subsection{Earthquake load application}

Seismic waves are random fluctuations, and their influencing factors are numerous and complex. Different earthquake ground motions and structural responses are also different [15]. Time-history analysis proves that the same structure uses different seismic wave input data to obtain different results [16]. The seismic load is applied by artificial synthetic waves. According to the Code for Seismic Design of Buildings (GB50011-2001) [17], the basic design parameters are as follows:

Table 3. Application of seismic loads.

\begin{tabular}{ccccc}
\hline $\begin{array}{c}\text { Seismic fortifica- } \\
\text { tion intensity }\end{array}$ & $\begin{array}{c}\text { Seismic accel- } \\
\text { eration }\end{array}$ & $\begin{array}{c}\text { Site fea- } \\
\text { ture cycle }\end{array}$ & $\begin{array}{c}\text { Acceleration time } \\
\text { history curve peak }\end{array}$ & $\begin{array}{c}\text { Response spectrum level seismic } \\
\text { influence coefficient maximum }\end{array}$ \\
\hline 8 degree & $0.30 \mathrm{~g}$ & $0.25 \mathrm{~s}$ & $310 \mathrm{~cm} / \mathrm{s}^{2}$ & 0.24 \\
\hline
\end{tabular}

The acceleration wave of the artificial wave applied to the seismic load is shown in Figure 3.

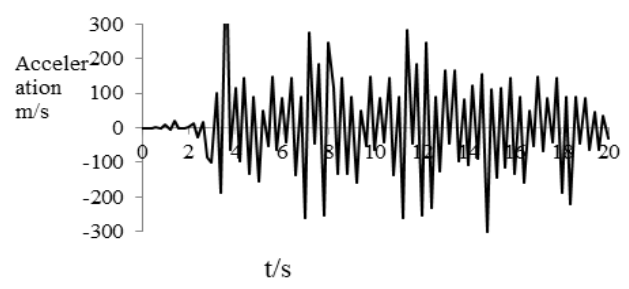

Figure 3. Earthquake horizontal acceleration wave.

For viscoelastic boundary conditions, the input of the boundary conditions must be in the (force) time course ${ }^{[18]}$. First, the acceleration time history is converted into a velocity time history by integration, and then converted into a corresponding stress input.
Use formula to transform velocity time history into stress time history:

$$
\begin{aligned}
& \sigma_{n}=-2\left(\rho C_{p}\right) v_{n} \\
& \sigma_{s}=-2\left(\rho C_{s}\right) v_{s}
\end{aligned}
$$

In this part:

$$
\sigma_{n} \longrightarrow \text { Normal stress; } \rho-\text { Density; } C_{p} \longrightarrow \mathrm{P}
$$
wave velocity of the medium; $v_{n}$ Vertical particle velocity; $\sigma_{s} \longrightarrow$ Shear stress; $C_{s} \longrightarrow \mathrm{S}$ wave velocity of the medium; $v_{s}$ _-Horizontal particle velocity.

The speed time history curve of the power input is shown in Figure 4. 


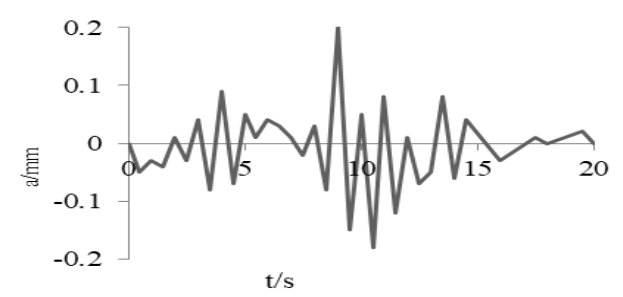

Figure 4. Speed time history curve of ower input.

Referring to the research results of Li Guangming ${ }^{[19]}$, the seismic load is applied in the $\mathrm{X}$ direction of a single machine foundation such as soil thickness $30 \mathrm{~m}$. After the load is applied, the transient analysis module of ABAQUS is used to analyze the dynamic time history of the large-diameter single-pile foundation structure of offshore wind power.

\section{Analysis of Bearing Capacity of Large Diameter Single Piles of Off- shore Wind Power Under Earth- quake Load.}

\subsection{Time history analysis results under seismic load}

According to the theoretical analysis of the bearing capacity characteristics of large-diameter single-pile offshore wind power, the vertical bearing capacity of large-diameter single piles is generally easier to meet the requirements. Therefore, the focus is on the analysis of the horizontal bearing capacity of largediameter single-pile offshore wind power.

\subsection{Influencing factors of bearing capacity of large diameter single piles in offshore wind power.}

It can be seen from Figure 5 that the maximum stress value of the large-diameter single-pile foundation structure of the offshore wind power reaches 13.766 $\mathrm{MPa}$, and the maximum displacement value is 0.720 $\mathrm{m}$. The finite element model constructed above is used as a reference to increase the amount of steel used for large-diameter single-pile foundations by $5 \%$ and $10 \%$. When the seismic load is applied, by changing the size of one part and controlling the other dimensions, the influence of the depth of the pile foundation, the diameter of the pile foundation and the wall thickness of the pile foundation on the bearing capacity of the large-diameter single-pile offshore wind power can be obtained. The model design dimensions and steel consumption are shown in Table 4.

Table 4. Large-diameter single-pile model size table for offshore wind power.

\begin{tabular}{cccccc}
\hline $\begin{array}{c}\text { Model } \\
\text { number }\end{array}$ & $\begin{array}{c}\text { Pile foundation } \\
\text { depth L/m }\end{array}$ & $\begin{array}{c}\text { Pile diame- } \\
\text { ter D/m }\end{array}$ & $\begin{array}{c}\text { Pile foundation } \\
\text { wall thickness } / \mathrm{m}\end{array}$ & $\begin{array}{c}\text { Increase in steel } \\
\text { consumption } / \%\end{array}$ & Description \\
\hline MX0 & 45 & 4 & 0.05 & 0 & Reference model \\
MX1 & 50 & 4 & 0.05 & $5 \%$ & Increase the depth of \\
pX2 & 55 & 4 & 0.05 & $10 \%$ & $5 \%$ foundation \\
MX3 & 60 & 4 & 0.05 & $5 \%$ & Increase pile diameter \\
MX4 & 45 & 5 & 0.05 & $10 \%$ & $5 \%$ \\
MX5 & 45 & 6 & 0.05 & $5 \%$ & Increase the wall thick- \\
MX6 & 45 & 7 & 0.05 & $10 \%$ & ness of the pile founda- \\
MX7 & 45 & 4 & 0.06 & $5 \%$ & tion \\
MX8 & 45 & 4 & 0.07 & 0.08 & \\
MX9 & 45 & 4 & & &
\end{tabular}

\subsubsection{Analysis of bearing capacity of different pile foundations in soil depth.}

This section mainly analyzes the influence of different pile foundation depth on the bearing capacity of large-diameter single-pile offshore wind power, and sets the pile diameter $\mathrm{D}$ to $4 \mathrm{~m}$, the pile foundation thickness $\mathrm{t}$ is $0.05 \mathrm{~m}$, and the offshore wind power large diameter single with different pile foundation depth. The pile bearing displacement curve is shown in Figure 5.

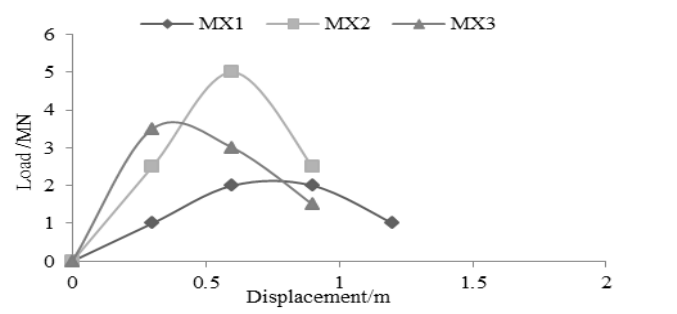

Figure 5. Load-displacement curve of large-diameter single pile with different pile foundation depth

It can be seen from Figure 5. That with the increase of pile foundation depth, the offshore wind power has a large diameter. The horizontal displacement of a single pile is gradually reduced. The time history curve of the pile top displacement under seismic load is shown in Figure 6. 


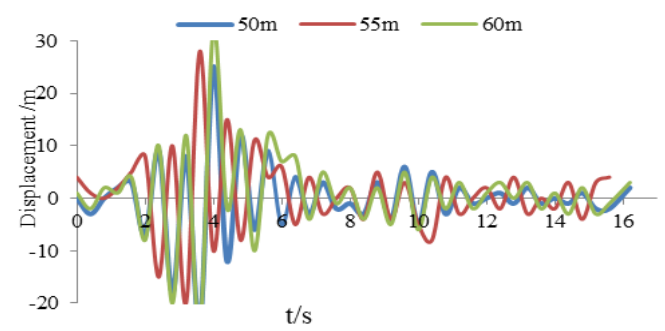

Figure 6. Time-history curve of pile top displacement

It can be seen from Figure 5. and Figure 6. that the horizontal deformation displacement of the pile foundation decreases as the pile foundation depth increases. This is because, with the increase of the depth of pile foundation, the horizontal displacement of the pile under the horizontal load is not easy to be deformed due to the hindrance of the subsoil. The horizontal displacement of the large-diameter single pile foundation of the offshore wind power is controlled, and the basic horizontal bearing capacity is controlled. Improved. However, after the depth of pile foundation is increased to a certain extent, increasing the depth of pile foundation will no longer have a significant impact on the development of horizontal displacement of large-diameter single-pile foundations.

\subsubsection{Analysis of bearing capacity of different pile foundation diameters.}

The horizontal load displacement curve of largediameter single-pile foundation of offshore wind power with different pile foundation diameter is shown in Figure 7.

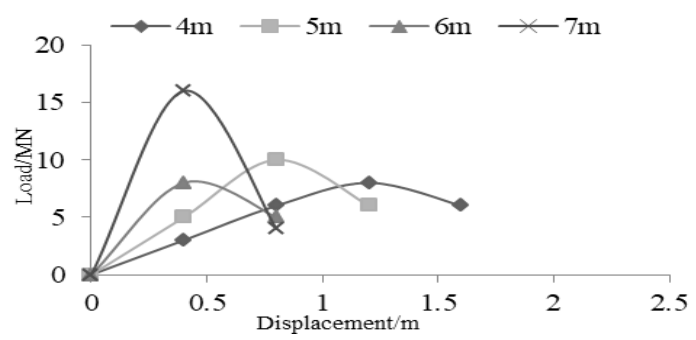

Figure 7. Displacement curve of large diameter single pile single foundation with different pile foundation diameter

It can be seen from Figure 11 that increasing the diameter of the pile foundation can significantly reduce the deformation of the large-diameter single pile foundation of the offshore wind power. Taking the pile foundation depth $\mathrm{L}$ of $45 \mathrm{~m}$ and the pile foundation thickness $t$ of $0.05 \mathrm{~m}$ as an example, when the pile foundation diameter is increased from $4 \mathrm{~m}$ to $7 \mathrm{~m}$, the horizontal displacement of the large-diameter singlepile foundation of offshore wind power is reduced by $60 \%$, reaching $1.4 \mathrm{~m}$, the displacement level of the large-diameter single pile foundation of offshore wind power is shown in Figure 8.

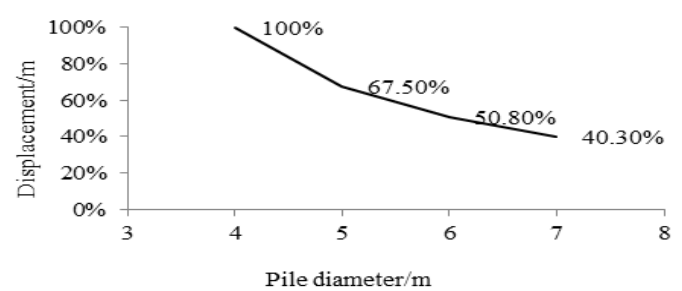

Figure 8. Offshore wind power large pile foundation displacement level.

It can be seen from Figure 8 . that as the diameter of the pile foundation increases, the displacement of the large-diameter single-pile foundation of the offshore wind power decreases gradually, and the pile foundation diameter increases from $4 \mathrm{~m}$ to $5 \mathrm{~m}$. The displacement of the large-diameter single-pile foundation of the offshore wind power is reduced. $32.5 \%$, while the pile foundation diameter increased from $5 \mathrm{~m}$ to $6 \mathrm{~m}$, and the displacement of the large-diameter single-pile foundation of offshore wind power was reduced by $10 \%$. Obtain the time history curve of the top displacement of the single pile foundation under seismic load, as shown in Figure 9.

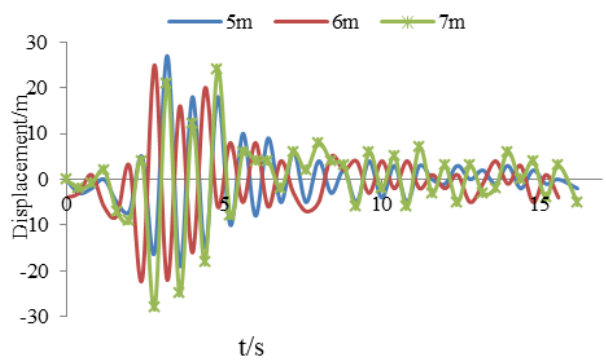

Figure 9. Top displacement time history curve of foundation diameter.

It can be seen from Figure 8. and Figure 9. that with the increase of the diameter of the single pile foundation, the horizontal bearing capacity of the large-diameter single pile foundation of the offshore wind power is obviously improved.

\subsubsection{Analysis of bearing capacity of different pile foundation wall thickness.}

The pile foundation depth $\mathrm{L}$ is $45 \mathrm{~m}$, the single pile foundation diameter $\mathrm{D}$ is $4 \mathrm{~m}$, and the pile foundation thickness $\mathrm{t}$ is set to $0.06 \mathrm{~m}, 0.07 \mathrm{~m}, 0.08 \mathrm{~m}$, respectively. The horizontal load displacement of the large-scale single-pile foundation of offshore wind power with different pile foundation thickness See Figure 10. 


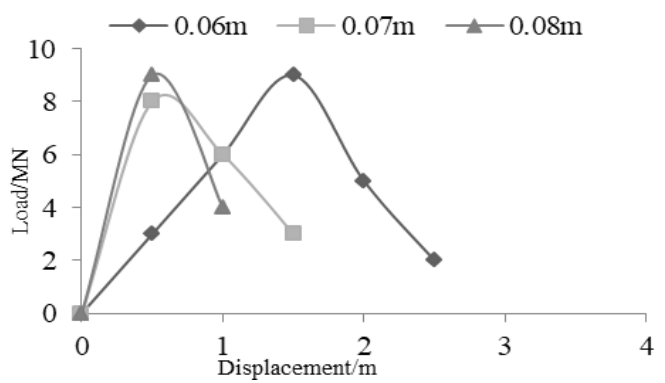

Figure 10. Displacement curve of large- curve of foundation diameter. diameter single pile foundation with different pile foundation wall thickness.

It can be seen from Figure 10. that the thicker the pile base wall thickness, the smaller the deformation of the offshore wind power large diameter single pile foundation. Because the wall thickness of the pile foundation increases, the elastic modulus and bending stiffness of the large-diameter single-pile offshore wind power are increased, and the deformation of the large-diameter single-pile offshore wind power is reduced under the same horizontal load, but the wall thickness of the pile foundation is increased. Large pairs of piles will increase the resistance during the piling process and increase the difficulty of piling ${ }^{[20]}$. The time history curve of the pile top displacement of the single pile foundation under seismic load is shown in Figure 11.

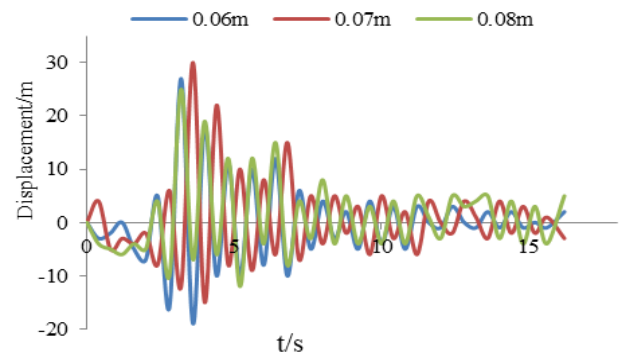

Figure 11. Time-history curve of pile top displacement of foundation wall thickness.

It can be seen from Figure 10. and Figure 11. that the increase of the wall thickness of the pile foundation is not proportional to the decrease of the horizontal deformation of the large diameter single pile at sea. As the wall thickness of the pile base continues to increase, the wind power large diameter single pile The rigidity of pile foundation increases, and the influence on the horizontal deformation of large diameter single-pile wind power is less and less. Therefore, in engineering application, the difficulty of pile driving and the deformation control of pile foundation should be considered [21], and the reasonable pile foundation wall should be selected. thick.

\section{Conclusion}

The ABAQUS finite element software is used to analyze the bearing characteristics and influencing factors of large-diameter single-pile offshore wind power under seismic loading. The main conclusions are as follows:
(1) The increase of pile foundation depth will significantly reduce the horizontal displacement at the top of large-diameter single pile. When the pile foundation depth increases to a certain extent, it will continue to increase the depth of the soil to the horizontal deformation of large-diameter single pile.

(2) The choice of the diameter of the pile foundation has a great influence on the horizontal deformation of the large-diameter single pile foundation. With the increase of the pile foundation diameter, the deformation of the large-diameter single pile foundation is reduced.

(3) With the increase of the pile foundation thickness, the horizontal displacement of the largediameter single pile foundation gradually decreases, and the increase of the pile foundation wall thickness directly increases the bending rigidity of the largediameter single pile, and the pile foundation wall thickness increases to After a certain degree, its influence on the horizontal deformation of large-diameter single pile foundation is no longer significant.

Based on the above conclusions, in the design of large-diameter single-pile offshore wind power, it is necessary to meet the horizontal displacement requirements of pile foundation under seismic load, select the pile-base design parameter combination of large-diameter buried depth, and select a reasonable pile foundation wall thickness to improve the large diameter single pile operation reliability, reducing the overall cost of the project.

\section{ACKNOWLEDGMENT}

This study was financially supported by the Project of Science and Technology Innovation Fund for graduate students of the Shandong University of Science and Technology (no. SDKDYC180212).

\section{References}

1. Liu, B.X., Tang, X.W. (2009) Analysis on combining pile of composite foundation. J. SHANXI ARCHITECTURE., 35: 95-96.

2. Wu, Z.J., Che, A.L., Ghen, T. (2011) Warming effects on permafrost under earthquake motions and seismic stability of pile foundation of dry bridge. J. Materials Research Innovations, 15: s586-s589.

3. Zhang, F., Jin, Y., Bao, X. (2010) Soil-water coupling finite element analysis on seismic enhancement effect of group-pile foundation with ground improvement. J. IOP Conference Series: Materials Science and Engineering, 10: 012108.

4. Wang, S.C., Liu, K.Y., Chen, C.H. (2015) Experimental investigation on seismic behavior of scoured bridge pier with pile foundation. J. Earthquake Engineering \& Structural Dynamics, 44: 849-864.

5. Lu, C.W. (2007) Numerical Study for Centrifugal Model Tests of a Single Pile Foundation Installed in Sandy Deposits. J. Journal of Mechanics, 23: 389398. 
6. Hsiung, Y.M. (2003) Theoretical elastic $\sim$ plastic solution for laterally loaded piles. J. Journal of Geotechnical and Geo environmental Engineering, 475-480.

7. Raongjant, W., Meng, J. (2011) Experimental investigation on seismic behavior of single piles in sandy soil[J]. Earthquake Engineering and Engineering Vibration, 2011, 10, 3: 417-422.

8. Banerjee, S., Lee, F. H. (2013) Centrifuge shaking table tests on a single pile embedded in clay subjected to earthquake excitation. J. International Journal of Geotechnical Engineering, 7, 2: 117-123.

9. Luan, M. T., Kong D. S., Lv, A. Z. (2005) Analysis of seismic response of pile-supported structures considering pile-soil interaction. J. Chinese Journal of Rock Mechanics and Engineering, 24, 1: 5061-5064.

10. Liao, S. T., Tong, J. H., Chen, C. H. (2006) Numerical simulation and experimental study of Parallel Seismic test for piles. J. International Journal of Solids and Structures, 43, 7: 2279-2298.

11. Fan, Q. L., Yu, R. B., Qi, L. (2017) Numerical analysis of horizontal bearing capacity of sea single pile foundation considering concrete damage and steel yielding. J. Journal of Basic science and engineering, 25, 5: 1026-1039.

12. Li, R. X., Zhang, J. W., Zhang Q. Y., Han, Y., Wei, M. (2018) Experimental study and numerical simulation fo horizontal bearing behavior of pile foundation with different slope angles, 13, 19: 2252-2257.

13. Zhang, S. Z., Zheng, Q. Z., Wang, J. J. (2013) Numerical analysis of dynamic response for single pile under horizontal seismic action. J. Journal of Water Resources \& Water Engineering, 24, 6: 6-10.

14. Kojima, K., Fujita, K., Takewaki, I. (2014) Unified analysis of kinematic and inertial earthquake pile responses via the single-input response spectrum method. J. Soil Dynamics and Earthquake Engineering, 63: 36-55.

15.Zhou, Y. B., Zhou, Q. P., Duan, Z. Q. (2019) Preliminary determination of the site effect and the influence range of surface earthguake of rock slope with different topographic and geologi. J. Science Technology and Engineering, 18, 33: 200-208

16. Li, X. L. (2019) The propagation law of single radial well fracturing based on extended finite element method. J. Science Technology and Engineering, 19, $7: 78-86$

17. Liu, Y., Xiao, Z. R., Jiang, M. M. (2019) Model test on influence of pile length on Pile resistance and bearing capacity characteristics. J. Science Technology and Engineering, 19, 7: 215-219

18. Guo, L. Q., Zhao, H. L., Wang, T. C., Zhang, X. S. (2019) Effect of varied axial force on the seismic performance of reinforced concrete shear walls. J. Science Technology and Engineering, 19, 2: 228238.

19. Li, G. M. (2013) The Seismic Study of Property of Prestressed Pipe Pile (PHC) foundations in High
Seismic Intensity Area. D. Hebei University of Technology.

20. Shimizu, S. (2011) Behaviour of steel columns under 3-D seismic load. J. Thin-Walled Structures, 49, 5: 544-553.

21. Chen, X. C., Wang, C. F., Liu, Z. W. (2013) Nonlinear Seismic Response Analysis Model and Experimental Verification for Pile Foundation of Bridge Structure. J. Applied Mechanics and Materials, 1993-1999. 